RUNNING HEAD: Nonverbal Communication in Politics

Nonverbal communication in politics:

A review of research developments, 2005-2015

\title{
Delia Dumitrescu
}

School of Politics, Philosophy, Language and Communication Studies

University of East Anglia

Norwich Research Park, Norwich, Norfolk, NR4 7TJ, UK

Delia.dumitrescu@gmail.com

Acknowledgment: The author would like to thank Erik Bucy and Gregg Murray for valuable feedback on this review article. 
Nonverbal communication in politics:

A review of research developments, 2005-2015

\begin{abstract}
This article reviews research contributions in political science and communication to the topic of nonverbal communication and politics from 2005 to 2015 . The review opens with research on the content of nonverbal communication, then considers studies examining what moderates the impact of nonverbal aspects of political messages on attitudes and behavior — and at the mechanisms that underpin these effects. Over the period reviewed here, research shows that the nonverbal channel is rich in political information and is consequential for political decisionmaking, particularly under certain circumstances, such as in low-information conditions. Visuals affect political decisions through cognitive and emotional routes. This review article also identifies several directions where further research is required, particularly with regard to social media, non-visual aspects of nonverbal communication, the interplay of visual and verbal arguments, and the mechanisms behind the effects of nonverbal communication.
\end{abstract}

Key words: nonverbal political communication; nonverbal communication content; nonverbal communication moderators; nonverbal communication mechanisms 
Nonverbal communication in politics is not unlike dark matter in the universe: it is everywhere and affects how citizens react to political events, evaluate politicians, and participate in political life. Yet, despite the ubiquity of nonverbal content in everyday political news coverage, we know comparatively little about the influence nonverbal information wields on public opinion and political behavior. Indeed, we still know much more about the power and limits of verbal argumentation in political discourse. This review article discusses some of the key results published over the course of a decade in the political science and political communication literature that advance knowledge in three directions: our understanding of the content of political nonverbal communication, conditions under which effects occur, and mechanisms of influence. Specifically, the review asks, and seeks to answer: What nonverbal political communication are citizens exposed to? Under what contingent conditions does nonverbal communication affect political attitudes and behavior? And, what are the mechanisms responsible for these effects?

With these questions in mind, this review is organized into three main parts. The first part covers recent studies describing the content of nonverbal communication in various media and different political contexts. The second part reviews research uncovering the moderators of nonverbal communication effects. And the third part reviews advances in our understanding of the mechanisms underpinning nonverbal influence. In each part we note the progress that has been made in addressing these questions and review current research directions. We conclude by highlighting the contribution of nonverbal analysis to political research more generally.

\section{Study selection procedure}

In gathering studies for the review, we followed the approach of Graber and Smith (2005). We restricted the search to articles only, as we agree with these authors that published refereed 
research tends "to capture the most recent scholarship from the broadest array of scholars" (p. 480). Moreover, we cover work published primarily in political science and political communication journals, as other recent reviews of nonverbal communication have examined published studies in the fields of communication (Schill, 2012), media and biopolitics (Bucy, 2011; forthcoming), and political ethology (Stewart, Salter, \& Mehu, 2009).

To obtain a broad range of recent political science and political communication scholarship speaking to our three broad questions, we used a wide-focused article selection procedure similar to Graber and Smith's (2005). In our case, we began with a search in the International Political Science Abstracts (IPSA) database, followed by a Google Scholar search in specific journals. The search query was limited to refereed articles published in or after 2005 that contained one of the following pairs of words in the article body, abstract or title: "political, visual," “political, nonverbal," “political, image," “communication, visual," “communication, nonverbal," and "communication, image." For the IPSA search, we only retained peer-reviewed journal publications written in English. For the Google Scholar searches, we targeted journals whose area of expertise included research on politics and communication. ${ }^{1}$ We then supplemented these results with additional studies cited by those identified by the search as well as articles suggested by reviewers. In total, this procedure produced 82 research articles.

\section{Nonverbal political communication content}

Because nonverbal communication is rich in content, some aspects have attracted significant interest (like television news coverage of campaigns or candidate facial displays), while for others the scientific investigation is still in its infancy (e.g., nonverbal content in social media or non-visual elements of nonverbal communication such as voice tone or background sound). 
When considering the volume of information available to the public, studies suggest that television covers politicians more through visual depictions than through their verbal statements, at least during key democratic moments such as elections. Bucy and Grabe's (2007) analysis of televised general election coverage in the U.S. shows that image bites (i.e., instances when candidates are only shown, but not heard) have grown significantly in length since the early 1990s, while sound bites have conversely shrunk. Esser's (2008) subsequent analysis across several European countries showed that image bites are widely used to cover politics on commercial channels.

In line with previous work in visual literacy (e.g., Kress \& Van Leeuwen, 1996), many studies find that visuals are rich in political information, which is transmitted both through what aspects of politics are depicted as well as how they are depicted (Banning \& Coleman, 2009; Barrett \& Barrington, 2005a; Bucy \& Grabe, 2008; Coleman \& Banning 2006; Dumitrescu, 2010; Goodnow, 2013; Herrick, Mendez, \& Pryor, 2015; Hoffman, 2011; Kalmoe \& Gross 2015; Kharroub \& Bas, 2015; Sulkin \& Swigger, 2008; Verser \& Wicks, 2006; Vliegenthart, 2012). Among studies that show the information value of what is depicted, a recurring finding is that the mere presence of a visual element in a campaign message signals immediate or future leader behavior. Thus, for example, the presence of group images (such as racial minorities or specific ideological groups) in winning-candidate ads correlates with their future legislative activity (Sulkin \& Swigger, 2008). Along similar lines, but in a different medium, Vliegenthart (2012) finds that, as Dutch party leaders have become key political decision-makers in the last decades of the twentieth century, they have also increasingly become the focus of party election posters.

The way visual elements are depicted also works to prime viewers about what is important to consider. In France, for example, candidates of major parties who benefit from capitalizing on their personal appeal are more likely to use large, close-up shots of themselves on 
their posters - and to make eye contact in their photos - than candidates of niche parties, for whom their personal appeal brings little gain (Dumitrescu, 2010). A recent study of the French extreme-right party National Front shows that as the party tries to widen its appeal without significantly changing its doctrine, its candidates also adopt a more personal visual strategy by displaying large, close-up photos of themselves on election campaign materials (Dumitrescu, forthcoming). Another study, looking at candidate portrayals in political advertising from the 2008 U.S. presidential campaign, found that McCain's attack ads about crime were more likely to feature darkened images of President Obama, which are prone to activating racial stereotypes and negative affect (Messing et al., 2016). Studies in diverse contexts and media thus illustrate how the visual content of political communication aims both to inform and influence what information voters rely on in their decisions by promoting stereotypical thinking or by highlighting certain aspects of a candidate's persona.

Numerous studies have analyzed the media framing of campaigns, zeroing in on campaign coverage (e.g., Banning \& Coleman, 2009; Barrett \& Barrington 2005a; Bucy \& Grabe, 2008; Coleman \& Banning 2006; Dan \& Iorgoveanu, 2013; Tsfati, Markowitz Elfassi, \& WaismelManor, 2010). Media bias emerges as the dominant theme of this work. An analysis of U.S. newspapers comparing the visual coverage of candidates showed that newspapers portray candidates they endorse more favorably by picturing them with a confident, smiling demeanor or surrounded by supporters (Barrett \& Barrington, 2005a, p. 612). Candidates the newspapers did not endorse were, conversely, portrayed displaying negative facial emotions, awkward body postures, and without supporters (Barrett \& Barrington, 2005a, p. 612).

Grabe and Bucy (2009) documented similar differences between frontrunners and trailing candidates, as well as debate "winners" and "losers," in their longitudinal analysis of U.S. general election news coverage from 1992 to 2004 . Trailing candidates and debate losers were shown 
more often in political news coverage exhibiting anger/threat and using defiant gestures, including finger pointing or wagging, making a fist, or shaking their head in disagreement (Grabe \& Bucy, 2009). In Israel, more attractive politicians were found to receive more news coverage even when controlling for other factors influencing their newsworthiness, such as political status (Tsfati et al., 2010). And an analysis of candidate portrayals in Romania found significant differences between depictions of male and female candidates, with the coverage of some female candidates focused more on their personal life (Dan \& Iorgoveanu, 2013).

Investigating visual bias in political news coverage generates varying results depending on the election year(s) analyzed, the timeframe of analysis, and how the concept is operationalized in content analysis measures. Looking at a single election, Banning and Coleman (2009) find no bias in the television network coverage of the 2000 U.S. presidential election. However, using a plenitude of measures to indicate bias, Grabe and Bucy (2009) document slightly more favorable visual framing for Republican candidates in their longitudinal analysis of general elections from 1992 to 2004 . When coverage is biased, such patterns are important to note, as evidence points to a significant correlation between the nonverbal presentation of the candidates (in terms of camera shots, facial expressions, and gestures) and citizens' positive and negative feelings about them (see Coleman \& Banning 2006; Coleman \& Wu, 2010).

Another key tenet of this research is the analysis of candidates' nonverbal behavior. Among the many different aspects of candidates' nonverbal communication, such as facial displays, demonstrative gestures, and voice tone, most research has focused on politicians' facial displays. For example, Stewart and Ford-Dowe (2013) use the Facial Action Coding System (FACS) to interpret President Barack Obama's facial expressions of emotion and extend earlier findings on televised leader displays (e.g., McHugo, Lanzetta, Sullivan, Masters, \& Englis, 1985). By comparing FACS coding to study participants' self-reports of the same expressions, 
they show that viewers can accurately detect reassuring, neutral, and threatening smiles but may be less skilled at differentiating between felt and amused smiles. In a similar vein, Stewart, Bucy, and Mehu (2015) employ FACS to inventory different smile types exhibited by Republican candidates' in the 2012 U.S. presidential primaries. They find considerable variation in candidate smiles, including posed, controlled, enjoyment, amusement, and contempt smiles, and show that viewers possess the ability to perceive the difference between them.

With the growth of digital video archives and increased access to historical footage, the content of nonverbal communication in politics can also be compared across different eras, as with Bucy's comparison of Richard Nixon and Barack Obama's first debate performances in 1960 and 2012 (see this issue). By coding the candidates' nonverbal behavior, Bucy investigates whether "losing" in a presidential debate is associated with a set of visible, empirically verifiable nonverbal indicators that correspond to physical weakness, pronounced stress, evasive or fearful behavior, and other outward signs of secondary or subordinate status. He finds that, indeed, there are reliable behavioral indicators of subordinate status. The hallmark signs of losing may include nonverbal indicators of stress and evasion, which show discomfort with camera attention and competitor challenges, or, in Nixon's case, physical frailty at the time of debate.

Nonverbal content in social media has grown extensively in recent years but has received significantly less attention than more traditional media, such as newspapers, television ads, and posters. An innovative study by Kharroub and Bas (2015) on the visuals circulated on Twitter during the 2011 Egyptian uprising reaches some interesting conclusions. The study finds that the timeline of the images posted, as well as the location of the user posting them (inside or outside Egypt, from an Arab or non-Arab country), influences image content. Moreover, the study finds that most images posted on Twitter surrounding this moment are intended to boost efficacy, depicting primarily crowds and protesters. Verser and Wicks (2006) conducted one of the first 
studies of online candidate images and found from their analysis of the 2000 U.S. presidential campaign that $\mathrm{Al}$ Gore not only used more images than George W. Bush but also was more likely to picture himself surrounded by people, often by regular voters. Looking a decade later at Obama and Romney's use of Facebook photographs, Goodnow (2013) found that both candidates utilized this space to convey images of themselves as good leaders, warm and likable politicians, and (again) to highlight their mass appeal.

Despite the best efforts to identify a diverse corpus of research for this review, the bulk of identified studies focus on the visual content of nonverbal political communication. Research about the information embedded in the auditory communication channel is much more scarce. One exception is Stewart's work on audience laugher in U.S. presidential debates, in which he finds that laughter varies with type of candidate smile (Stewart, 2010). Another exception is a study about the selection of male versus female voiceovers in political campaign ads in the U.S (Strach et al., 2015). Male voiceovers are significantly more common, while female voiceovers are more likely to feature ads associated with "women's issues" (e.g., education, health care) and on other ads intended for a mostly female audience. Moreover, female voiceovers are more likely to be used in contrast and negative ads, while positive, image-building ads are more likely to feature male voices. As the authors observe, female voices may mitigate some of the negative aspects associated with political disagreement, making conflict more acceptable to viewers (Strach et al., 2015).

Discussion. The studies in the period under review cement the conclusion of previous scholarship with regard to the richness in information of nonverbal communication content and its prominence in political news coverage (for an extensive review, see Grabe \& Bucy, 2009). In addition, the surge of studies conducted outside the U.S. context (e.g., in Israel, France, Romania, the Netherlands) should be regarded as a positive research development since cultural context 
plays an influential role in nonverbal communication expression and reception, and not all findings about politics within particular national settings can be generalized across countries.

At the same time, this overview highlights some gaps in knowledge about the content of nonverbal communication in politics. A large part of the continuing research focuses on political candidates, rather than on other actors, such as citizens, activists, and office holders at different levels. More research is needed to map the nonverbal content of governmental and other institutional communications, as well as the nonverbal strategies of other political and social groups, including pressure groups, unions and civic associations, and even terrorist organizations. Moreover, despite the increased use of Facebook and Twitter for political communication, much recent scholarship covers nonverbal communication in traditional media, focusing on television and newspapers. More information about the character of images and videos circulating on social media is needed to keep pace with citizens' increasing use of these channels for political information and action.

\section{Moderators of nonverbal communication effects}

Beyond the content of nonverbal political communication, an important question revolves around the extent to which citizens' exposure to nonverbal information matters for forming political evaluations, making voting decisions, and engaging in political participation. The evidence reviewed here suggests that the size of the impact of nonverbal information is conditional on several factors, first and foremost on the availability of additional information at the time of decision-making. We therefore begin by reviewing the evidence pointing to nonverbal effects under different information conditions, then review the influence of other moderators.

There is strong evidence that nonverbal cues matter when citizens have little other issue or candidate information to guide decision-making. In low-information elections, for example, about 
which voters know virtually nothing, candidate images do affect evaluations (e.g., Ahler, Citrin, Dougal, \& Lenz, 2016; Banducci, Karp, Thrasher, \& Rallings, 2008; Lev-On \& Waismel-Manor, this issue). More evidence connecting candidate facial images and vote choice emerges from studies where individuals select a candidate after very quick exposure to their visuals in the absence of other information. Several of these "thin-slice forecast" studies (e.g., Laustsen \& Petersen, 2016; Lawson, Lenz, Baker, \& Myers, 2010; Mattes \& Milazzo, 2014; Mattes et al., 2010; Milazzo \& Mattes, 2016; Praino, Stockemer, \& Ratis, 2014) uncover a sizable correlation between candidates' facial features, trait evaluations, and their electoral success at the polls. The information encoded in candidate facial displays is mostly related to their attractiveness and competence - a point discussed at more length in the next section.

Evidence about the automatic encoding of and reliance on nonverbal cues in lowinformation conditions extends to other visuals. Kemmelmeier and Winter (2008) find that simply being in a room with a flag decorating the wall activates nationalist and group dominance attitudes. Kalmoe and Gross (2015) confirm this conclusion, finding that flag displays at election times can affect those who score high on symbolic patriotism and racial prejudice. And citizens exposed to party campaign materials containing the European Union flag are, when cognizant of the flag's display, more likely to see these party elites as pro-European in the absence of other information about their positions (Dumitrescu \& Popa, this issue).

The importance of viewers' informational context for the impact of nonverbal communication emerges also from research focused on voter characteristics, particularly political sophistication and strength of partisanship. Stockemer and Praino (2015) find that attractiveness serves as a heuristic cue for uninformed voters but not for political sophisticates. A similar finding emerges from a series of large $N$ experiments with student participants in the UK, with those with low levels of political information and participation intent more likely to endorse a 
more attractive candidate (Johns \& Shepard, 2011). Similarly, Lenz and Lawson (2011) find that U.S. voters with low levels of political sophistication are more likely to reward candidates based on their appearance. And a carefully constructed experimental study with visuals of actual candidates in several 2012 high-profile U.S. gubernatorial and senatorial elections also finds that poorly informed voters reward candidates for their facial attractiveness (Ahler et al., 2016).

In addition, some results suggest that those with weak partisan affiliations are more likely to rely on attractiveness as an evaluative cue. Independent voters in U.S. senate elections, for instance, place a higher premium on candidates' facial features than committed partisans (Atkinson, Enos, \& Hill 2009). And weak partisans prefer candidates made to look more like themselves (Bailenson, Iyengar, Yee, \& Collins, 2008).

Nevertheless, while the availability of information is generally important, it does not always moderate nonverbal communication effects. For example, the nonverbal confidence that candidates show influences voter evaluations no matter the quality of the argument made (Dumitrescu, Gidengil, \& Stolle, 2015). This result is consistent with findings from a German study in which Haumer and Donsbach (2009) found that a politician's active nonverbal style during a debate increases perceptions of leadership ability, irrespective of verbal arguments or the audiences' or debate host's reactions. Moreover, several studies find that both high and low sophisticates rely on visual cues when they are distracted (Hart, Ottati, \& Krumdick, 2011), when presented with portrayals that suggest competence (e.g., candidates sitting behind a desk, Brusattin 2012), and when voting in low key elections (e.g., for the California statehouse, Ahler et al., 2016). And a rare study looking at viewers' reactions to emotional displays by ordinary citizens in television news stories finds that viewers across different levels of socioeconomic status increase their participation intentions after exposure to such stories (Bas \& Grabe, this issue). 
Interesting as these findings are, the precise interplay between nonverbal influence and verbal information on viewer decision-making is not yet fully understood. To achieve a high level of experimental control, most nonverbal communication studies hold the verbal information constant or provide only a limited amount of it. When voters have access to larger quantities of policy or ideological information, one study finds that nonverbal behavior matters little for the evaluation, at least in the context of a German debate (Nagel, Maurer, \& Reinemann, 2012). However, studies from the U.S. contradict this finding and consistently find more influence for nonverbal communication (Shah, Hanna, Bucy, Wells, \& Quevedo, 2015; Shah et al., this issue). Considering this discrepancy, the German study used footage of somewhat unexpressive candidates in a non-experimental setting; thus, it is possible that such effects depend on who the candidates are, their communication style or degree of expressivity, the quality of information provided both verbally and nonverbally, and the cultural context of the communication. As Maurer argues in this issue, the relative influence of verbal and nonverbal aspects of political communication may also fluctuate during an extended message presentation.

Another recent study provides additional insight: Powell, Boomgaarden, De Swert, and de Vreese (2015) find that, when news visuals depicting a foreign conflict are accompanied by news text, the emotional impact of visuals is stronger on behavioral intentions than on opinions. Thus, visual influence may depend on the outcome measured and a full explanation of visual effects may require the measurement of diverse, politically relevant outcomes.

The impact of other moderators, such as the gender and race of the person portrayed, has also been documented, although not as amply as the impact of information. Laustsen and Petersen (2016) find that candidate gender influences the signaling power of facial features on election outcomes. Specifically, facial dominance benefits male candidates with conservative audiences; in conflict situations, both male and female viewers prefer leaders with dominant faces. However, 
female candidates with dominant features (e.g., with masculine traits) are more likely to perform worse in elections than candidates without these features. Female candidates who make agentic hand gestures, such as assertive, expressive or choppy movements, are likely to be punished for them, compared to male candidates who are likely to increase their voter support (Everitt, Best \& Gaudet, this issue).

Evidence also points to the influence of skin color on viewer reactions. Ostfeld (2015) finds that Whites are more willing to express comfort with immigrant neighbors who have lighter skin tones and stereotypical Eurocentric features_-but these visual markers do not affect their more general immigration attitudes. Building on previous work on visual framing (e.g., Gilliam \& Iyengar, 2000), Messing and colleagues (2016) find that short exposures to candidates with dark skin complexions activate stereotypes and negative affective responses toward Blacks. However, at least in one U.S.-based study, participants also attributed more positive traits, such as a better work ethic and greater trustworthiness, to darker skinned candidates - while at the same time evaluating them as less experienced and less intelligent (Weaver, 2012).

As with studies examining the interplay between visual and verbal message elements, more research is needed to better understand when visible markers of gender and race influence voter decisions, and when the viewer's gender and race matters. Bailenson, Garland, Iyengar, and Yee (2006) provide some indication that the effect of visual appearance is different for male than for female viewers (with male viewers more likely to endorse a candidate who looks more like themselves). In an extension of previous visual framing research (e.g., Iyengar, 1996), one study documents how exposure to pictures of victims of Hurricane Katrina impacts viewers differently based on their race. Ben-Porath and Shaker (2010) find that when White viewers are exposed to hurricane victim photographs, they blame the government less for the humanitarian disaster that ensued - an effect that does not occur among Black viewers. Again, more evidence is needed to 
map the role played by demographic characteristics in moderating the impact of nonverbal information.

Since elections play a quintessential role in democracies, many studies are interested in pinning down how various aspects of candidate nonverbal communication affects voter evaluations. In line with earlier results from still image studies (e.g., Rosenberg, Bohan, McCafferty \& Harris, 1986; Rosenberg, Kahn, \& Tran, 1991), a favorable visual depiction of a candidate can impact voting intentions and candidate-related assessments even when viewers are provided with additional contextual information (Barrett \& Barrington, 2005b; Brusattin, 2012; Horiuchi, Komatsu \& Nakaya, 2012). By experimentally manipulating one of President George W. Bush's speeches, Stewart, Waller, and Schubert (2009) provide strong evidence for the capacity of microexpressions of reassurance to mitigate feelings of threat and anger in viewers. Other results suggest that contextual aspects of political visuals matter as well. For example, groups depicted in political ads offer cues about candidate policy positions (Swigger, 2012). Moreover, according to another U.S.-based study, politicians can increase voter support for themselves and their policies by pairing their foreign policy statements with threatening visuals (Gadarian, 2014).

Several studies are broadening research vistas in nonverbal political communication by incorporating new variables or contexts and merging datasets in innovative ways. One direction is to examine the impact of nonverbal communication as a predictor of social media expression during mass political events like presidential debates. Shah and colleagues (2015) are among the first to examine on a large scale the close relationship between verbal and nonverbal content on television and the volume and sentiment of Twitter expression via the "second screen" in a realtime election setting (see also Shah et al., this issue). From their analysis of the 2012 presidential debates in the U.S., they find that several features of both Barack Obama and Mitt Romney's 
nonverbal presentation elicited strong reactions among social media users, especially expressions of anger/threat displayed by Romney and affinity gestures made by Obama.

On a different note, focusing on an often-neglected aspect of nonverbal communication, a study by Klofstad (2015) looks at the impact of voice pitch. This study suggests that voters prefer candidates with lower-pitch voices, especially when running against a male opponent. This result confirms earlier results by Klofstad and colleagues, who found that vote appeals made by men and women with lower-pitch voices were more persuasive than when made in a higher-pitch voice (Klofstad, Anderson, \& Peters 2012).

Another promising line of research concerns the influence of background visuals and use of reaction shots in televised debates. Seiter and Weger (2005) find that viewers rely on the nonverbal reactions of debate opponents to judge the appropriateness of the speaking candidate; specifically, in this study, speakers' appropriateness was highest when the debate opponent expressed constant nonverbal disagreement (such as through head shaking from left to right and eye rolling). Haumer and Donsbach (2009) found in their experimental televised debate study that perceptions of a candidate's integrity and personal qualities suffered when the moderator and studio audience displayed negative nonverbal reactions.

In the context of print media, Friedman and Sutton (2013) considered the impact of background visuals that were completely disconnected from the primary message. Readers' reactions to a war story were placed on the same page as an image-oriented ad for luxury items such as jewelry, high-class watches, or cars; the presence of the ad decreased concern for war victims. At the same time, background visuals were shown not to be consequential in a series of field experiments conducted by Matland and Murray (2015). These studies failed to replicate earlier results, which posited that incidental exposure to the display of someone's eyes in a getout-the-vote campaign message will increase voter turnout. Across various races and using 
multiple variants of the eyes visual (male and female), Matland and Murray (2015) found that such imagery had no impact on turnout.

Discussion. This body of evidence on the moderators of nonverbal communication effects shows, perhaps unsurprisingly, that nonverbal information has the strongest impact on politically relevant attitudinal and behavioral outcomes when shown and processed in isolation from other sources of information, or for individuals who are low on political sophistication. Importantly, however, nonverbal effects persist when individuals possess more information as well, such as when they are politically sophisticated (Ahler et al., 2016), or have the opportunity to listen to a politician's speech (Dumitrescu et al., 2015).

An important research direction is to better explain the interplay between visual and verbal information effects. Moreover, as the list of potential moderators of nonverbal effects is, for now, far from being complete, more research is needed to answer the general question about what individual differences are of greatest consequence for the impact of visuals on political decision-making. For example, studies considering demographic influences should better specify the conditions under which men are more likely than women to rely on nonverbal information and how viewers' racial background conditions their reactions to racial cues. While the evidence on these issues is mounting, further research is required to elucidate some aspects on which there appears to be conflicting or incomplete evidence.

Several findings also suggest new, mostly unexplored, avenues of research. For example, it would be important to know if, as some studies suggest, nonverbal effects are stronger for certain political outcomes than for others. At least two studies find that political visuals have a stronger impact on behavioral intentions than on attitudes (Ostfeld, 2015; Powell et al., 2016), But these studies are quite unique in tackling the problem of what dependent variable is most affected by exposure to nonverbal communication. More is needed. 
Another area that deserves additional attention is the impact of nonverbal communication on new modes of participation, such as live tweeting, Facebook posting, and other second-screen behavior during political events. The picture of a Syrian boy washed away on the sea shore in the fall of 2015 generated an outpour of collective sympathy worldwide; the distribution of this picture, and the public behavioral response that followed was strongly facilitated by social media. As discussed in the previous section, Kharroub and Bas (2015) find that emotive images of citizens circulated on social media can have a mobilization effect. When are these pictures consequential—and for whom—are, as yet, unanswered questions.

Moreover, there are some enticing results suggesting that incidental exposure to nonverbal information in the background of a political message may impact viewer perceptions. Such results come, for example, from studies on the impact of audience or moderator reactions in televised debates (e.g., Haumer \& Donsbach, 2009) and from studies on the effects of accompanying advertising that surrounds political messaging (e.g., Friedman \& Sutton, 2013). But the conditions under which this contextualizing information becomes pertinent to viewers are still under specified. These studies, and others that do not find such effects (see Matland \& Murray, 2015), raise questions about the content of political visuals required to influence perceptions, and whether viewers take these incidental visuals into account when forming attitudes but not when deciding on behavioral intentions.

Finally, just as we know little about the content of aural aspects of nonverbal communication, we also know little about their effects. While music and voice are known to convey emotion (e.g., Brader, 2005; Klofstad, 2015), when they matter most is still an empirical question waiting to be answered.

\section{Mechanisms behind nonverbal communication effects}


Considerable evidence shows that visuals affect decision-making by acting as judgmental shortcuts, especially when viewers are evaluating political leaders. Much of the research speaking to these heuristic-based mechanisms focuses on the inferences that viewers automatically make from politicians' facial displays and facial features.

The halo effect, the tendency of better-looking individuals to be evaluated more positively, emerges from several studies. There is a significant correlation between candidates' attractiveness scores and their electoral support in several democracies (e.g., Berggren, Jordahl, \& Poutvaara, 2010; Laustsen, 2014; Rosar, Klein, \& Beckers, 2008). Experimental studies show that under conditions of low information (either because there is no information available, or because voters have low levels of sophistication), voters tend to endorse more attractive candidates (Ahler et al., 2016; Johns \& Shepard, 2011; Lenz \& Lawson, 2011; Lev-On \& Waismel-Manor, this issue; Stockemer \& Praino 2015), and to assign to them their preferred beliefs (Herrmann \& Shikano, 2016). Under certain circumstances, better-looking candidates garner more support from politically sophisticated citizens as well, such as when they are distracted or evaluating candidates in low-profile elections (Ahler et al., 2016; Hart et al., 2011). Beyond the halo effect, why better looking candidates garner political support is still a matter of investigation. Some findings suggest that the relationship between attractiveness and vote choice is mediated by perceptions of competence (Laustsen, 2014).

The relationship between perceptions of candidate competence and facial features has received significant attention, building on the seminal work of Todorov and colleagues (for a review, see Hall, Goren, Chaiken, \& Todorov, 2009). Evaluations of competence made solely on the basis of facial features after short exposures positively correlate with election outcomes in several studies (e.g., Laustsen, 2014; Lawson et al., 2010). Spezio, Loesch, Gosselin, Mattes, and Alvarez (2012) provide some preliminary evidence that citizens are able to correctly infer 
competence not just from faces, but also from body posture and clothes. Missing from this line of research, however, is a more detailed explanation of how voters can actually infer competence from facial features (or clothes), since competence involves a complex set of skills. It appears that perceptions of competence inferred from facial features correlate with issue position attributions, as people are more likely to assign their preferred views to candidates judged to be competent (Herrmann \& Shikano, 2016). Again, though, more research is needed to clarify the relationship between inferences of competence and candidate support.

Another stream of research has examined the relationship between politicians' physical attributes and citizen perceptions of leadership. Experiments conducted by Murray (2014) and Murray and Schmitz (2011) show that citizens are more likely to attribute leadership abilities to taller individuals with an imposing physical stature (as defined by body mass index). In line with an evolutionary outlook, Murray and Schmitz (2011) also found that individuals with a larger physical stature tend to assign greater leadership qualities to themselves, and thus are more likely to pursue leadership positions. Laustsen and Petersen (2015) also find support for an evolutionary basis to leadership perceptions and leader selection. From experimental evidence, they find that individuals with dominant facial features are preferentially chosen to lead in contexts requiring collective action against threats, while individuals with less dominant facial features are predominantly preferred as friends.

Other aspects of politicians' faces have received more limited attention. For example, baby-faced individuals are more trusted to make compromises in negotiations (Maoz, 2012). This finding fits well with Laustsen and Petersen's (2015) study on facial dominance, which finds that individuals with dominant facial features are more trusted in situations involving conflict. Voters also rely on the sex-typicality of a politician's face (i.e., how feminine or masculine their facial traits are) to infer the politician's party affiliation (Carpinella \& Johnson, 2013). Given the 
significant party system variations across democracies, the relationship between facial sextypicality and inferred partisanship should be replicated beyond the U.S. context.

Other heuristics rely on the extent to which known and unknown politicians are visually able to appear familiar to voters. People endorse candidates with facial appearances similar to their own, and this effect is stronger for those with weak or no partisan attachment (Bailenson et al., 2008). Candidates who fit other familiar stereotypes or expectations may also be better off: at least for Republican candidates in the U.S., the sex typicality of facial features is positively correlated with electoral success (Carpinella, Hehman, Freeman, \& Johnson, 2016).

Studies have also provided evidence about the mechanism behind viewer reactions to some types of negative nonverbal information. In line with previous work on inappropriate leader displays (see Bucy, 2011), Gong and Bucy (2016) show that Obama and Romney were punished by viewers for inappropriate nonverbal display behaviors during the 2012 presidential debates. Using eye-tracking data, they find that inappropriate facial displays drew extensive visual attention to the source of the violation, eliciting negative evaluations in the process. Another study, examining the impact of exposure to negative nonverbal information in the form of television news coverage of war, found that when negative visuals were the most vivid, viewers had good recognition memory for the images but poor recall for the audio message accompanying them (Hutchinson \& Bradley, 2009). This pattern of results suggests that negative visuals may direct voters' attention away from verbal aspects of the political message.

Finally, nonverbal communication has been shown to influence viewers by generating emotional reactions. Brader (2005) for example, used negative visuals and music to induce anxiety among participants. Similarly, racial cues in an immigration study led viewers to feel greater anxiety, which in turn mediated effects on immigration attitudes (Brader, Valentino \& 
Suhay, 2008). Sirin, Valentino, and Villalobos (this issue) find that racial cues generate empathy with those depicted among in-group members.

Discussion. There is enough evidence to support at least two mechanisms that explain the effects of nonverbal information on behavioral and attitudinal outcomes in politics. On the one hand, a large body of research shows that a frequent mechanism through which political nonverbals influence decisions is based on association of candidate images and political qualities. Nonverbals in this regard are taken to signal desired qualities or outcomes. On the other hand, political visuals generate emotions, which in turn orient attention and cognitive responses. Both these mechanisms merit additional investigation.

With respect to image-based heuristics, more research is needed to explain how a candidate's competence, partisanship, or ideological preference can be accurately inferred from thin slice exposures, and how nonverbal features other than faces (e.g., voice tone) are integrated into decision-making. Competence, ideology, and partisanship can be complex aspects of a candidate's profile and may vary with the party system. This complexity can thus be difficult to reconcile, particularly with such short duration exposures merely to a candidate's face. A potential avenue to explain these results may be provided by evolutionary approaches (e.g., Laustsen \& Petersen, 2015; Murray, 2014), but more investigation in this direction is required, With respect to the second mechanism, there is little doubt that exposure to nonverbal communication generates emotion in viewers. However, recent research in this respect has focused less on the connection between visuals and the ensuing emotions, and more on the consequences of inducing certain emotional states on behavior. Seminal studies conducted by Masters and colleagues in the 1980s and 1990s (e.g., Masters et al., 1986; Sullivan \& Masters 1988, 1993) showed that leaders are able to reliably induce emotions in viewers through their facial displays. Further research should consider the extent to which other nonverbal signals, 
whether from politicians, ordinary citizens, or news coverage, induce similar emotional responses, and the extent to which these responses mediate the effects of nonverbal communication on decision-making.

\section{Conclusion}

Nonverbal communication in politics is an exciting, and now vast, topic of study. Considerable knowledge has accumulated about the content and effects of political visuals and nonverbal behavior, and the body of political science and communication studies reviewed in this article advances this knowledge. In line with previous scholarship, the studies reviewed here show that political visuals contain substantial information regarding what voters should know about a candidate. Visuals also function as an important element of the decision-making process, particularly for those who do not possess other information. However, even for sophisticates, political visuals still play a key role in the decision-making process. They serve as heuristics and decisional shortcuts, eliciting emotions and cognitions while impacting political attitudes and behavior.

As already hinted throughout this review, many aspects of nonverbal communication in politics remain unexplored. Perhaps due to the relative novelty of social media, we know comparatively little of the content of nonverbal communication on this platform, and on the quality of visuals and videos circulated on social media for public mobilization. There are still many facets to explore when it comes to the auditory aspect of nonverbal communication, such as the impact of voice tone, pitch, and other qualities. We have also yet to fully explore the moderating effect of viewer characteristics, or of emotional responses, on the persuasive impact of nonverbal communication. Then there are matters to elucidate with respect to the relative importance of visual and verbal communication for voter decision making, particularly during 
extended political broadcasts. In short, there is a possibility rich research agenda ahead, and we look forward to reflecting back on new developments and discoveries in an updated research review a decade from now. 


\section{References}

Ahler, D. J., Citrin, J., Dougal, M. C., \& Lenz, G. S. (2016). Face value? Experimental evidence that candidate appearance influences electoral choice. Political Behavior, 1-26. doi: 10.1007/s11109016-9348-6.

Atkinson, M. D., Enos, R. D., \& Hill, S. J. (2009). Candidate faces and election outcomes: Is the face-vote correlation caused by candidate selection? Quarterly Journal of Political Science, 4(3), 229-249.

Bailenson, J. N., Garland, P., Iyengar, S., \& Yee, N. (2006). Transformed facial similarity as a political cue: A preliminary investigation. Political Psychology, 27(3), 373-385.

Bailenson, J. N., Iyengar, S., Yee, N., \& Collins, N. A. (2008). Facial similarity between voters and candidates causes influence. Public Opinion Quarterly, 72(5), 935-961.

Banducci, S. A., Karp, J. A., Thrasher, M., \& Rallings, C. (2008). Ballot photographs as cues in lowinformation elections. Political Psychology, 29(6), 903-917.

Banning, S., \& Coleman, R. (2009). Louder than words: A content analysis of presidential candidates' televised nonverbal communication. Visual Communication Quarterly, 16(1), 4-17.

Barrett, A. W., \& Barrington, L. W. (2005a). Bias in newspaper photograph selection. Political Research Quarterly, 58(4), 609-618.

Barrett, A. W., \& Barrington, L. W. (2005b). Is a picture worth a thousand words? Newspaper photographs and voter evaluations of political candidates. Harvard International Journal of Press/Politics, 10(4), 98-113.

Bas, O, \& Grabe, M. E. (this issue). Personalized news and participatory intent: How emotional displays of everyday citizens promote political involvement. American Behavioral Scientist.

Ben-Porath, E. N., \& Shaker, L. K. (2010). News images, race, and attribution in the wake of Hurricane Katrina. Journal of Communication, 60(3), 466-490.

Berggren, N., Jordahl, H., \& Poutvaara, P. (2010). The looks of a winner: Beauty and electoral success. Journal of Public Economics, 94(1), 8-15. 
Brader, T. (2005). Striking a responsive chord: How political ads motivate and persuade voters by appealing to emotions. American Journal of Political Science, 49(2), 388-405.

Brader, T., Valentino, N. A., \& Suhay, E. (2008). What triggers public opposition to immigration? Anxiety, group cues, and immigration threat. American Journal of Political Science, 52(4), 959978.

Brusattin, L. (2012). Candidate visual appearance as a shortcut for both sophisticated and unsophisticated voters: Evidence from a Spanish online study. International Journal of Public Opinion Research, 24(1), 1-20.

Bucy, E. P. (in press). Media biopolitics: The emergence of a subfield. In S. A. Peterson \& A. Somit (Eds.), Handbook of biology and politics. Cheltenham, UK: Edwin Elgar Publishing.

Bucy, E. P. (this issue). The look of losing, then and now: Nixon, Obama, and nonverbal indicators of opportunity lost. American Behavioral Scientist.

Bucy, E. P. (2011). Nonverbal communication, emotion, and political evaluation. In E. Konijn, K. Koveling, \& C. von Scheve (Eds.), Handbook of emotions and mass media (pp. 195-220). New York: Routledge.

Bucy, E. P., \& Grabe, M. E. (2007). Taking television seriously: A sound and image bite analysis of presidential campaign coverage, 1992-2004. Journal of Communication, 57(4), 652-675.

Bucy, E. P., \& Grabe, M. E. (2008). "Happy warriors" revisited: Hedonic and agonic display repertoires of presidential candidates on the evening news. Politics and the Life Sciences, 27(1), 78-98.

Carpinella, C. M., \& Johnson, K. L. (2013). Appearance-based politics: Sex-typed facial cues communicate political party affiliation. Journal of Experimental Social Psychology, 49(1), 156-160.

Carpinella, C. M., Hehman, E., Freeman, J. B., \& Johnson, K. L. (2016). The gendered face of partisan politics: Consequences of facial sex typicality for vote choice. Political Communication, 33(1), 2138. 
Coleman, R., \& Banning, S. (2006). Network TV news' affective framing of the presidential candidates: Evidence for a second-level agenda-setting effect through visual framing. Journalism \& Mass Communication Quarterly, 83(2), 313-328.

Coleman, R., \& Wu, H. D. (2010). Proposing emotion as a dimension of affective agenda setting: Separating affect into two components and comparing their second-level effects. Journalism \& Mass Communication Quarterly, 87(2), 315-327.

Dan, V., \& Iorgoveanu, A. (2013). Still on the beaten path: How gender impacted the coverage of male and female Romanian candidates for European office. International Journal of Press/Politics, 18(2), 208-233.

Dumitrescu, D. (2010). Know me, love me, fear me: The anatomy of candidate poster designs in the 2007 French legislative elections. Political Communication, 27(1), 20-43.

Dumitrescu, D. (in press). Up, close and personal: The new National Front visual strategy under Marine Le Pen. French Politics.

Dumitrescu, D., Gidengil, E., \& Stolle, D. (2015). Candidate confidence and electoral appeal: An experimental study of the effect of nonverbal confidence on voter evaluations. Political Science Research and Methods, 3(1), 43-52.

Dumitrescu, D., \& Popa, S. A. (this issue). Showing their true colors? How EU flag display affects perceptions of party elites' European attachment. American Behavioral Scientist.

Esser, F. (2008). Dimensions of political news cultures: Sound bite and image bite news in France, Germany, Great Britain, and the United States. International Journal of Press/Politics, 13(4), 401428.

Everitt, J., Best, L. A., \& Gaudet, D. (this issue). Candidate gender, behavioral style, and willingness to vote: Support for female candidates depends on conformity to gender norms. American Behavioral Scientist.

Friedman, R. S., \& Sutton, B. (2013). Selling the war? System-justifying effects of commercial advertising on civilian casualty tolerance. Political Psychology, 34(3), 351-367. 
Gadarian, S. K. (2014). Scary pictures: How terrorism imagery affects voter evaluations. Political Communication, 31(2), 282-302.

Gilliam, Jr., F. D., \& Iyengar, S. (2000). Prime suspects: The impact of local television news on attitudes about crime and race. American Journal of Political Science, 44(3), 560-573.

Gong, Z. H., \& Bucy, E. P. (2016). When style obscures substance: Visual attention to display appropriateness in the 2012 presidential debates. Communication Monographs, 83(3), 349-372.

Goodnow, T. (2013). Facing off: A comparative analysis of Obama and Romney Facebook timeline photographs. American Behavioral Scientist, 57(11), 1584-1595.

Grabe, M. E., \& Bucy, E. P. (2009). Image bite politics: News and the visual framing of elections. Oxford University Press.

Graber, D. A., \& Smith, J. M. (2005). Political communication faces the 21st century. Journal of Communication, 55(3), 479-507.

Hall, C. C., Goren, A., Chaiken, S., \& Todorov, A. (2009). Shallow cues with deep effects: Trait judgments from faces and voting decisions. In Borgida, E., Federico, C. M., \& Sullivan, J. L. (Eds.), The political psychology of democratic citizenship (pp. 73-99). Oxford University Press.

Hart, W., Ottati, V. C., \& Krumdick, N. D. (2011). Physical attractiveness and candidate evaluation: A model of correction. Political Psychology, 32(2), 181-203.

Haumer, F., \& Donsbach, W. (2009). The rivalry of nonverbal cues on the perception of politicians by television viewers. Journal of Broadcasting \& Electronic Media, 53(2), 262-279.

Herrick, R., Mendez, J. M., \& Pryor, B. (2015). Razor's edge: The politics of facial hair. Social Science Quarterly, 96(5), 1301-1313.

Herrmann, M., \& Shikano, S. (2016). Attractiveness and facial competence bias: Face-based inferences of candidate ideology. Political Psychology, 37(3), 401-417.

Hoffman, K. S. (2011). Visual persuasion in George W. Bush's presidency: Cowboy imagery in public discourse. Congress \& the Presidency, 38(3), 322-343. 
Horiuchi, Y., Komatsu, T., \& Nakaya, F. (2012). Should candidates smile to win elections? An application of automated face recognition technology. Political Psychology, 33(6), 925-933.

Hutchinson, D., \& Bradley, S. D. (2009). Memory for images intense enough to draw an administration's attention: Television and the "war on terror." Politics and the Life Sciences, 28(1), 31-47.

Iyengar, S. (1996). Framing responsibility for political issues. ANNALS of the American Academy of Political and Social Science, 546(1), 59-70.

Johns, R., \& Shephard, M. (2011). Facing the voters: The potential impact of ballot paper photographs in British Elections. Political Studies, 59(3), 636-658.

Kalmoe, N. P., \& Gross, K. (2015). Cueing patriotism, prejudice, and partisanship in the age of Obama: Experimental tests of U.S. flag imagery effects in presidential elections. Political Psychology, doi: 10.1111/pops.12305.

Kemmelmeier, M., \& Winter, D. G. (2008). Sowing patriotism, but reaping nationalism? Consequences of exposure to the American flag. Political Psychology, 29(6), 859-879.

Kharroub, T., \& Bas, O. (2015). Social media and protests: An examination of Twitter images of the 2011 Egyptian revolution. New Media \& Society, doi: 10.1177/1461444815571914.

Klofstad, C. A. (2015). Candidate voice pitch influences election outcomes. Political Psychology, DOI: $10.1111 /$ pops.12280.

Klofstad, C. A., Anderson, R. C., \& Peters, S. (2012). Sounds like a winner: voice pitch influences perception of leadership capacity in both men and women. Proceedings of the Royal Society B: Biological Sciences, 279(1738), 2698-2704.

Kress, G. R., \& Van Leeuwen, T. (1996). Reading images: The grammar of visual design. Psychology Press.

Laustsen, L. (2014). Decomposing the relationship between candidates' facial appearance and electoral success. Political Behavior, 36(4), 777-791. 
Laustsen, L., \& Petersen, M. B. (2015). Does a competent leader make a good friend? Conflict, ideology and the psychologies of friendship and followership. Evolution and Human Behavior, 36(4), 286293.

Laustsen, L., \& Petersen, M. B. (2016). Winning faces vary by ideology: How nonverbal source cues influence election and communication success in politics. Political Communication, 33(2), 188-211.

Lawson, C., Lenz, G. S., Baker, A., \& Myers, M. (2010). Looking like a winner: Candidate appearance and electoral success in new democracies. World Politics, 62(04), 561-593.

Lenz, G. S., \& Lawson, C. (2011). Looking the part: Television leads less informed citizens to vote based on candidates' appearance. American Journal of Political Science, 55(3), 574-589.

Lev-On, A. \& Waismel-Manor, I. (this issue). Looks that matter: The effect of physical attractiveness in low and high information elections. American Behavioral Scientist.

Maoz, I. (2012). The face of the enemy: The effect of press-reported visual information regarding the facial features of opponent politicians on support for peace. Political Communication, 29(3), 243256.

Matland, R. E., \& Murray, G. R. (2015). I only have eyes for you: Does implicit social pressure increase voter turnout? Political Psychology, DOI: 10.1111/pops.12275

Mattes, K., \& Milazzo, C. (2014). Pretty faces, marginal races: Predicting election outcomes using trait assessments of British parliamentary candidates. Electoral Studies, 34, 177-189.

Mattes, K., Spezio, M., Kim, H., Todorov, A., Adolphs, R., \& Alvarez, R. M. (2010). Predicting election outcomes from positive and negative trait assessments of candidate images. Political Psychology, 31(1), 41-58.

Maurer, M. (this issue). Nonverbal influence during televised debates: Integrating CRM in experimental channel studies. American Behavioral Scientist.

McHugo, G. J., Lanzetta, J. T., Sullivan, D. G., Masters, R. D., \& Englis, B. G. (1985). Emotional reactions to a political leader's expressive displays. Journal of Personality and Social Psychology, 49(6), 1513-1529. 
Messing, S., Jabon, M., \& Plaut, E. (2016). Bias in the flesh: Skin complexion and stereotype consistency in political campaigns. Public Opinion Quarterly, 80(1), 44-65.

Milazzo, C., \& Mattes, K. (2016). Looking good for Election Day: Does attractiveness predict electoral success in Britain? British Journal of Politics \& International Relations, 18(1), 161-178.

Murray, G. R. (2014). Evolutionary preferences for physical formidability in leaders. Politics and the Life Sciences, 33(1), 33-53.

Murray, G. R., \& Schmitz, J. D. (2011). Caveman politics: Evolutionary leadership preferences and physical stature. Social Science Quarterly, 92(5), 1215-1235.

Nagel, F., Maurer, M., \& Reinemann, C. (2012). Is there a visual dominance in political communication? How verbal, visual, and vocal communication shape viewers' impressions of political candidates. Journal of Communication, 62(5), 833-850.

Ostfeld, M. (2015). The backyard politics of attitudes toward immigration. Political Psychology, doi: 10.1111/pops.12314.

Powell, T. E., Boomgaarden, H. G., De Swert, K., \& de Vreese, C. H. (2015). A clearer picture: The contribution of visuals and text to framing effects. Journal of Communication, 65(6), 997-1017.

Praino, R., Stockemer, D., \& Ratis, J. (2014). Looking good or looking competent? Physical appearance and electoral success in the 2008 congressional elections. American Politics Research, 42(6), 10961117.

Rosar, U., Klein, M., \& Beckers, T. (2008). The frog pond beauty contest: Physical attractiveness and electoral success of the constituency candidates at the North Rhine-Westphalia state election of 2005. European Journal of Political Research, 47(1), 64-79.

Rosenberg, S. W., Bohan, L., McCafferty, P., \& Harris, K. (1986). The image and the vote: The effect of candidate presentation on voter preference. American Journal of Political Science, 108-127.

Rosenberg, S. W., Kahn, S., \& Tran, T. (1991). Creating a political image: Shaping appearance and manipulating the vote. Political Behavior, 13(4), 345-367. 
Schill, D. (2012). The visual image and the political image: A review of visual communication research in the field of political communication. Review of Communication, 12(2), 118-142.

Seiter, J. S., \& Weger, H., Jr. (2005). Audience perceptions of candidates' appropriateness as a function of nonverbal behaviors displayed during televised political debates. Journal of Social Psychology, 145(2), 225-236.

Shah, D. V., Hanna, A., Bucy, E. P., Lassen, D. S., Van Thomme, J., Bialik, K., Yang, J. H., \& Pevehouse, J. (this issue). Verbal, tonal, and visual influences during presidential debates: Assessing effects on the volume and valence of online expression in real time. American Behavioral Scientist.

Shah, D. V., Hanna, A., Bucy, E. P., Wells, C., \& Quevedo, V. (2015). The power of television images in a social media age: Linking biobehavioral and computational approaches via the Second Screen. ANNALS of the American Academy of Political and Social Science, 659(1), 225-245.

Sirin, C. V., Valentino, N. A., \& Villalobos, J. D. (this issue). Group empathy in response to nonverbal racial/ethnic cues: A national experiment on immigration policy attitudes. American Behavioral Scientist.

Spezio, M. L., Loesch, L., Gosselin, F., Mattes, K., \& Alvarez, R. M. (2012). Thin-slice decisions do not need faces to be predictive of election outcomes. Political Psychology, 33(3), 331-341.

Stewart, P. A. (2010). Presidential laugh lines: Candidate display behavior and audience laughter in the 2008 primary debates. Politics and the Life Sciences, 29(2), 55-72.

Stewart, P. A., \& Ford Dowe, P. K. (2013). Interpreting President Barack Obama's facial displays of emotion: Revisiting the Dartmouth group. Political Psychology, 34(3), 369-385.

Stewart, P. A., Bucy, E. P., \& Mehu, M. (2015). Strengthening bonds and connecting with followers: A biobehavioral inventory of political smiles. Politics and the Life Sciences, 34(1), 73-92.

Stewart, P. A., Salter, F. K., \& Mehu, M. (2009). Taking leaders at face value: Ethology and the analysis of televised leader displays. Politics and the Life Sciences, 28(1), 48-74.

Stewart, P. A., Waller, B. M., \& Schubert, J. N. (2009). Presidential speechmaking style: Emotional response to microexpressions of facial affect. Motivation and Emotion, 33(2), 125-135. 
Stockemer, D., \& Praino, R. (2015). Blinded by beauty? Physical attractiveness and candidate selection in the U.S. House of Representatives. Social Science Quarterly, 96(2), 430-443.

Strach, P., Zuber, K., Fowler, E. F., Ridout, T. N., \& Searles, K. (2015). In a different voice? Explaining the use of men and women as voiceover announcers in political advertising. Political Communication, 32(2), 183-205.

Sulkin, T., \& Swigger, N. (2008). Is there truth in advertising? Campaign ad images as signals about legislative behavior. Journal of Politics, 70(1), 232-244.

Sullivan, D. G., \& Masters, R.D. (1988). “Happy warriors”: Leaders' facial displays, viewers' emotions, and political support. American Journal of Political Science 32(2), 345-68.

Sullivan, D. G., \& Masters, R.D. (1993). Nonverbal behavior, emotions, and democratic leadership. In G. E. Marcus \& R. L. Hanson (eds.) Reconsidering the democratic public, (pp. 307-332). University Park, PA: Pennsylvania State University Press.

Swigger, N. (2012). What you see is what you get: Drawing inferences from campaign imagery. Political Communication, 29(4), 367-386.

Tsfati, Y., Elfassi, D. M., \& Waismel-Manor, I. (2010). Exploring the association between Israeli legislators' physical attractiveness and their television news coverage. International Journal of Press/Politics, 15(2), 175-192.

Verser, R., \& Wicks, R. H. (2006). Managing voter impressions: The use of images on presidential candidate websites during the 2000 campaign. Journal of Communication, 56(1), 178-197.

Vliegenthart, R. (2012). The professionalization of political communication? A longitudinal analysis of Dutch election campaign posters. American Behavioral Scientist, 56(2), 135-150.

Weaver, V. M. (2012). The electoral consequences of skin color: The "hidden" side of race in politics. Political Behavior, 34(1), 159-192. 


\section{Endnotes}

${ }^{1}$ These journals were: American Journal of Political Science, American Political Science Review, American Politics Research, British Journal of Political Science, British Journal of Politics \& International Relations, Communication Monographs, Communication Research, Communication Review, European Journal of Political Research, International Journal of Press/Politics, International Journal of Public Opinion Research, Journal of Communication, Journal of Politics, Journalism \& Mass Communication Quarterly, New Media \& Society, Political Behavior, Political Communication, Political Psychology, Political Research Quarterly, Politics and the Life Sciences, Public Opinion Quarterly, and Social Science Quarterly. 